\title{
Nucleophilic stabilization of water-based reactive ink for titania-based thin film inkjet printing
}

Gadea, Christophe; Marani, Debora; Esposito, Vincenzo

Published in:

Journal of Physics and Chemistry of Solids

Link to article, DOI:

10.1016/j.jpcs.2016.10.004

Publication date:

2017

Document Version

Peer reviewed version

Link back to DTU Orbit

Citation (APA):

Gadea, C., Marani, D., \& Esposito, V. (2017). Nucleophilic stabilization of water-based reactive ink for titaniabased thin film inkjet printing. Journal of Physics and Chemistry of Solids, 101, 10-17.

https://doi.org/10.1016/j.jpcs.2016.10.004

\section{General rights}

Copyright and moral rights for the publications made accessible in the public portal are retained by the authors and/or other copyright owners and it is a condition of accessing publications that users recognise and abide by the legal requirements associated with these rights.

- Users may download and print one copy of any publication from the public portal for the purpose of private study or research.

- You may not further distribute the material or use it for any profit-making activity or commercial gain

- You may freely distribute the URL identifying the publication in the public portal 


\title{
Nucleophilic stabilization of water-based reactive ink for titania-based thin film inkjet printing \\ C. Gadea*, D. Marani and V. Esposito
}

\author{
DTU Energy, Technical University of Denmark, Risф Campus, Frederiksborgvej 399, \\ DK - 4000 Roskilde, Denmark
}

\begin{abstract}
Drop on demand deposition (DoD) of titanium oxide thin films $(<500 \mathrm{~nm})$ is performed via a novel titanium-alkoxide-based solution that is tailored as a reactive ink for inkjet printing. The ink is developed as water-based solution by a combined use of titanium isopropoxide and nmethyldiethanolamine (MDEA) used as nucleophilic ligand. The function of the ligand is to control the fast hydrolysis/condensation reactions in water for the metal alkoxide before deposition, leading to formation of the $\mathrm{TiO}_{2}$ only after the jet process. The evolution of the titanium-ligand interactions at increasing amount of MDEA is here elucidated in terms of long term stability. The ink printability parameter $(\mathrm{Z})$ is optimized, resulting in a reactive solution with printability, $\mathrm{Z},>1$, and chemical stability up to 600 hours. Thin titanium oxide films $(<500 \mathrm{~nm})$ are proved on different substrates. Pure anatase phase is obtained after annealing at low temperature $\left(\mathrm{ca} .400{ }^{\circ} \mathrm{C}\right)$.
\end{abstract}

Keywords: Inkjet, thin film, sol-gel, rheology, Titania.

*Corresponding author: chga@ dtu.dk 


\section{Introduction}

Inkjet printing of inorganic materials has been spreading over the past years in several key technologies such as energy devices, sensors, electronics, biomedical applications and flexible electronics [1-8]. Research on inkjet printing of metal nanoparticles [[9]] and carbonaceous materials [[10]] have also been conducted. Such a rapid development is mainly due to its unique advantage of enabling a precise and selective deposition of materials into different architectures (thin films, 2D and 3D structures) with a very high resolution and minimal waste of materials [11-14]. The inkjet printing owns the further merits of being a low cost technique based on inks that can be easily formulated to be environmentally friendly. This fully meets the increasing demand on industry and academy to develop water-based systems for a more sustainable processing of materials [15-17].

Inkjet printing for inorganic materials is typically based on colloidal suspensions, i.e. a system containing oxide particles as solid loading. After deposition the printing is consolidated into a dense body either by the curing of special binders or via sintering process at high temperatures [12]. However, such a high temperature step might be incompatible with other components and substrates. In addition the formulation of a colloidal ink for inkjet printing requires very restrictive conditions in terms of particle size distribution and maximum solid loading, making colloidal inks challenging to design, stabilize and process $[12,18]$.

Among alternatives particle-free systems to the colloidal approach, such as UV curable dielectric inkjet inks [[19]], an interesting one is using a reactive ink based on sol gel solutions. While reactive inkjet exists in diverse forms [[20-23]], sol-gel chemistry is a well-consolidated and versatile process which is used to synthesize metal oxide thin films and nano-structured 
materials at low temperature. By a combination of sequential reactions at room temperature, hydrolysis of metal alkoxide to form intermediate oxo-polymers and metal oxide polymeric condensation (by either dehydration or de-alcoholation), widely interconnected, extended and highly homogeneous 3D oxo-precursor structure is obtained [24]. Compared to the conventional colloidal approach, a lower consolidation temperature of such a precursor material is then expected, making reactive ink an attractive alternative. However, the alkoxide precursor can be extremely reactive towards the hydrolysis/condensation and highly sensitive to the presence of water at the different step of the printing. Zirconium, titanium, and tungsten alkoxides are just few examples of such high reactive precursors which cannot be used directly in presence of water. Such a strong reactivity makes the development of sol-gel solutions for inkjet printing in aqueous medium challenging. Dry conditions or specific atmospheres are generally required to manipulate these compounds and avoid uncontrolled reactions. Moreover, if not properly controlled, the ink could early react at the nozzle or even at the reservoir, leading to severe clogging of the printer.

A fine control over the sol-gel process can be achieved by nucleophilic ligands. These stabilize the alkoxides by coordinating the metallic center and forming more stable molecular complexes precursors [25]. The hydrolysis/condensation reactions are thus inhibited and tolerance towards water is then achieved. Among the most used ligands there are carboxylic acids (e.g. acetic acid) [25] and alkanol amines (e.g. triethanolamine and methyldiethanolamine) [26,27]. Acidic ligands promote the rutile phase via a linear condensation of the reactants, whereas the anatase phase with a branched-like morphology is generally obtained in basic conditions [18-20]. A fine control of the precursors' reactivity is thus critical for the final morphology. However, unreactive ink can lead to wet and not resolved printings, with difficulties in the post-printing steps (i.e. drying, calcination, curing etc.). On the other hand, since chelating agent introduce 
electrostatic attraction in the solution, an excess of ligands can change the rheological properties, modifying the printability properties of the reactive inks.

In this work, we design a water-based $\mathrm{TiO}_{2}$ reactive ink both with suitable printability features and characterized by remarkable long term stability. Titania is selected as case study for its high relevance in a variety of strategic technologies and because its potential of inkjet printing (either as colloidal or sol-gel ink) has been long proven [28-33]. Moreover, while the influence of ligands on the final properties of water-based titania reactive ink has been reported in a few cases [33], at the best of our knowledge, no studies describe the formulation and use of waterbased reactive $\mathrm{TiO}_{2}$ inks considering inkjet printability criteria and the limitations in the long term stability $[26,27]$. Further, we use an environmental friendly amine methyl-diethanolamine (MDEA) as basic nucleophilic ligand for the first time in water-based solution. This is selected to promote branch-like anatase polymerization which potentially better suit inkjet printing dropby-drop processing.

\section{Experimental}

\subsection{Ink preparation}

Titanium (IV) isopropoxide (Ti(OPr) $)_{4}$, hereafter TiTIP) (Sigma-Aldrich) was the titanium alkoxide precursor used in this study while n- methyldiethanolamine (MDEA, Sigma-Aldrich) was added as nucleophilic ligand to inhibit the reaction hydrolysis/condensation process. Mixing was carried out under argon to avoid uncontrolled reactions (i.e. hydrolysis and condensation) between air moisture and the metal precursor. TiTIP and MDEA were mixed and stirred for 5 minutes. Ethanol-water solution at 40-60 vol\% ratio was separately prepared and slowly added to the TiTIP/MDEA blend and mixed for 5 minutes. To study the effect of MDEA on the final ink properties, inks at different molar 
ratio of complexation (i.e. $x=[\mathrm{MDEA}] /[\mathrm{TiTIP}]=2,4,6,8$ and 10) have been prepared. Titanium concentration in the ink was kept at $\mathrm{c}=0.1 \mathrm{mg} / \mathrm{l}$. The inks at different $x$ are hereafter indicated as Ink $x$, where $x$ refers to the molar ratio complexation and thus varies from 2 to 10 .

\subsection{Ink characterization}

Rheological properties of the inks were explored using an Anton Paar rheometer (MCR 302), in rotational mode and at a constant temperature of $21^{\circ} \mathrm{C}$. A plate-plate measuring system was used with a diameter of $50 \mathrm{~mm}$ (PP50) and at gap distance of $0.5 \mathrm{~mm}$ under a solvent trap. The experiments were performed using three steps of pre-treatment: the first one at $0.1 \mathrm{~s}^{-1}$ for 1 min followed by 1 min at rest $\left(0 \mathrm{~s}^{-1}\right.$ shear rate), and the third one at $10 \mathrm{~s}^{-1}$ for $1 \mathrm{~min}$. Flow curve measurements were conducted in step mode using 60 steps with a waiting time of $10 \mathrm{~s}$. The shear rates investigated range from $1 \mathrm{~s}^{-1}$ up to $100 \mathrm{~s}^{-1}$, in the up-ramp, and from $100 \mathrm{~s}^{-1}$ to $1 \mathrm{~s}^{-1}$ in the down-ramp. Viscosity was measured over time, from a few hours after preparation up to 1200 hours (50 days) in order to estimate the long term stability. Ink surface tension was measured using a bubble pressure tensiometer (BP 50, Krüss), and density was evaluated by weighing $10 \mathrm{ml}$ of ink. The printability of the inks was determined by calculation of their $Z$ numbers defined as:

$$
Z=\frac{\sqrt{\sigma \rho a}}{\eta}
$$

where $\eta$ is the ink viscosity (mPa.s), $\sigma$ is the surface tension $(\mathrm{mN} / \mathrm{m}), \rho$ is the density $\left(\mathrm{g} / \mathrm{cm}^{3}\right)$, and $a$ is the characteristic length $(\mu \mathrm{m})$ [35]. The parameter $a$ is typically taken as the diameter of the printing nozzles [35].

Transmission FTIR spectra of the liquid inks were recorded in the 4000 to $400 \mathrm{~cm}^{-1}$ region, using a Perkin Elmer Spectrum Two spectrometer to clarify interactions between ligand and titanium central atom. The evolution of the crystallographic phase for material deriving from Ink4, was investigated 
using solid state detector, $0.01^{\circ}$ step size, and $0.5 \mathrm{~s}$ step time (Bruker D8, Cu K $\alpha$ radiation) and a hot chamber (MRI high temperature stage). A few droplets of ink aged for 600 hours were dropped onto a platinum band inside the furnace chamber and diffraction patterns were recorded at different temperature between $100^{\circ}$ and $750^{\circ} \mathrm{C}$ using heating rate of $5^{\circ} \mathrm{C} / \mathrm{s}$ in a flow of air. Platinum XRD pattern was used as internal reference and crystallite size was determined using Scherrer Equation [36]. The value of the $\mathrm{Cu}-\mathrm{K} \alpha$ radiation used for determination is $0.15406 \mathrm{~nm}$ and the $\mathrm{k}$ value is equal to 1 .

Thermal analysis (DTA/TG) was performed on inks using a STA 409 PG (Netzsch) at a constant rate of $10 \mathrm{~K} \mathrm{~min}^{-1}$ under air.

\subsection{Thin films deposition and characterization}

Substrates used in this study are soda lime glass (Sigma Aldrich), indium tin oxide (ITO, Sigma Aldrich) and polycrystalline alumina (Keral 96, Kerafol). The surface free energy of the substrates has been measured using the methodology described in [[37]]. A commercially available thermal printer (HP Deskjet 1010) was used as a printing unit. The printer was modified to allow printing on flat and thick substrates (rigid or flexible) [12]. A compatible cartridge (HP 301 black) providing a 600 x 300 dpi resolution was cleaned to remove the original black ink and used to print the sol-gel inks. The cartridge contains 336 nozzles each having a diameter of $20 \mu \mathrm{m}$. To demonstrate the versatility of the inks a high resolution piezoelectric based printer (Pixdro LP 50) was also used. This printer is also equipped with a fiducial camera to observe droplet ejection. The print-heads are Spectra S class 128, equipped with 128 nozzles (nozzle diameter: $50 \mu \mathrm{m}$ ), using a firing frequency of $2.4 \mathrm{kHz}$. The waveform consisted in a $1 \mu$ s pulse to reach a voltage of $120 \mathrm{~V}$, followed by a dwell of $1 \mu$ s before going down to $0 \mathrm{~V}$ in $1 \mu \mathrm{s}$. The droplet velocity is $3 \mathrm{~m} / \mathrm{s}$. Printability numbers described earlier have been calculated based on the HP printer features. Each print made with both printers consists of a single layer. The printed layers were fired at $400^{\circ} \mathrm{C}$ for one hour in air using a chamber furnace, with a 
heating ramp of $100^{\circ} \mathrm{C} / \mathrm{h}$. Surface of the printed films was investigated by SEM (SUPRA 35, Zeiss) and with a numeric camera (NIKON D800).

\section{Results and discussion}

\subsection{Inks properties}

The printability of an inkjet ink is mainly controlled by its density, surface tension and viscosity [30, 31]. For these physical properties, ranges of values ensuring the printability of the inks have been identified and associated with a dimensionless parameter indicated as $\mathrm{Z}$ number. Several authors attempted to define a reliable printability domain using the $\mathrm{Z}$ number. For instance, Jang et al.[40] proposed a range between 4 and 14, whereas Derby et al. [35] suggested values between 1 and 10 . When $\mathrm{Z}$ number is outside this domains either no, poor or hardly stable and reproducible droplets can be can be ejected from the nozzle due to inadequate viscosity and/or surface tension values [35]. The printability of the inks developed in this work was estimated with respect to both printability ranges.

In the case of reactive inks, the stability towards the hydrolysis/condensation process is a further crucial factor that affects printing behavior. In this regard, the selection of a suitable nucleophilic ligand and the identification of its optimal amount with respect to the alkoxide precursors is the main challenge. In order to identify the optimal amount of MDEA, a series of inks having different molar complexation ratio $x=2,4,6,8,10$ were investigated for their viscosity, surface tension, and density and the corresponding $\mathrm{Z}$ number was then calculated. Figure 1 shows the flow curves for the five prepared inks 4 hours after the preparation, while the inset plot shows the corresponding viscosity curves. All the prepared inks exhibited a Newtonian behavior with constant viscosity independent on the shear conditions (inset). Accordingly, the viscosity values were simply determined from the slope of the flow curves. The obtained values together with measured values of the surface tension and the derived $\mathrm{Z}$ values for all the inks are reported in table 1. A trend as function of the MDEA amount can be 
identified with the Ink4 possessing the lowest viscosity. The corresponding MDEA amount can be then recognized as the optimal amount that minimizes the interactions among the reactive components of the ink, thereby hindering the hydrolysis/condensation process. At lower amount of ligand (e.g. Ink2) a slightly higher viscosity value is obtained likely as a result of an inefficient "shielding" of the alkoxide towards water. Interestingly, when the amount of the ligand exceeds the optimal value (e.g. Ink6, 8, 10), even higher viscosity values are observed and likely associated with polycondensation of the alkoxide-ligand complexes [41]. However, the increments of MDEA content does not impact on the surface tension (see Table 1) as the observed values only vary in a range of few $\mathrm{mN} / \mathrm{m}$. For the printability, while all the inks (four hours after the preparation) possess a $\mathrm{Z}$ number within the printability domain defined by Derby et.al. [35] $(1<\mathrm{Z}<10)$, only ink4 is within the domain defined by Jang et.al. $(4<\mathrm{Z}<14)[40]$.

The long-term stability of the prepared inks was then evaluated following the evolution of the rheology behavior over time. Except for the ink4 that maintained its Newtonian behavior on long-term, the other inks exhibited a transition to shear thinning flow, with a deviation from the Newtonian behavior that varies depending on the MDEA content. The shear thinning character of the inks was evaluated via the estimation of the flow index. This parameter can be mathematically determined via the analysis of rheological data using the logarithmic form of the power law [42]:

$$
\log (\tau)=\log (K)+n \log (\dot{\gamma})
$$

where $\tau$ is the shear stress, $\dot{\gamma}$ the shear rate, $\mathrm{K}$ the consistency coefficient and $\mathrm{n}$ the flow index. This corresponds to a linear equation in which the flow index $n$ is the slope identifying the character of the fluid: Newtonian when $n=1$, shear-thinning when $n<1$ and shear-thickening when $n$ is $>1$. Figure 2(a) shows the obtained values as function of the ageing time for all the developed inks. A slight and slow decrease of the flow index from the unit to around 0.93 and 0.98 was observed for the Ink2 and Ink6 
respectively, whereas a rapid and marked variation down to 0.76 and 0.67 was obtained for the Ink8 and Ink10, respectively. An increment over time of the viscosity was also observed for all the inks as indicated in Figure 2(b), where the viscosity at $100 \mathrm{~s}^{-1}$ for each inks is plotted as function of the MDEA concentration for three selected ageing times: $4 \mathrm{~h}, 600 \mathrm{~h}$, and $1200 \mathrm{~h}$ (see also Table 1). Ink4 is characterized by a slight variation of the viscosity values (less than $30 \mathrm{mPa}$ ), whereas larger increments are detected for the other inks. Specifically, after $1200 \mathrm{~h}$ the viscosity values of Ink2 and Ink6, with a similar trend, increases of around 50-60 mPa s, while for Ink8 and Ink10 variation within a range of hundreds of $\mathrm{mPa} \mathrm{s}$ is observed. Interestingly, all the inks after $1200 \mathrm{~h}$ are still transparent solution and no signals of $\mathrm{TiO}_{2}$ precipitation could be depicted as indicated in the inset picture. This experimental finding is consistent with the formation of clear monolithic gels when a ligand is used with an alkoxide (titanium alkoxides) [41]. The rheological analysis clearly indicates a superior stability for the Ink4. The persistence of the Newtonian character over a long period indicates that the interactions among the components are efficiently and fully minimized and minimal alteration of this stable state occurs (e.g. small increasing of the viscosity). For Ink2 and Ink6 only slight differences from Ink4 are observed. By contrast, significant deviations are observed for Ink8 and ink10 [41]. The resulting increment of the viscosity can be explained as an effect of the increased internal interactions among the constituents that also cause the shear thinning flow behavior. Remarkably, no variations in the surface tension over time at fixed amount of MDEA are observed for all the inks (see Table 1). This designates the viscosity as the only physical properties changing and affecting the printability of the developed inks. After $600 \mathrm{~h}$ of ageing, Ink4 is the only ink still within the printability domain defined by Derby, whereas after an ageing of $1200 \mathrm{~h}$ none of the inks exhibits a $\mathrm{Z}$ number value within such a domain. Interestingly, none of the inks exhibit a printability number within Jang's domain even after $600 \mathrm{~h}$. 
To confirm the hypothesis of a polycondensation at the highest content of ligand and clarify the ligand interactions with the central atom (Ti), inks stored during $600 \mathrm{~h}$ were characterized by FTIR

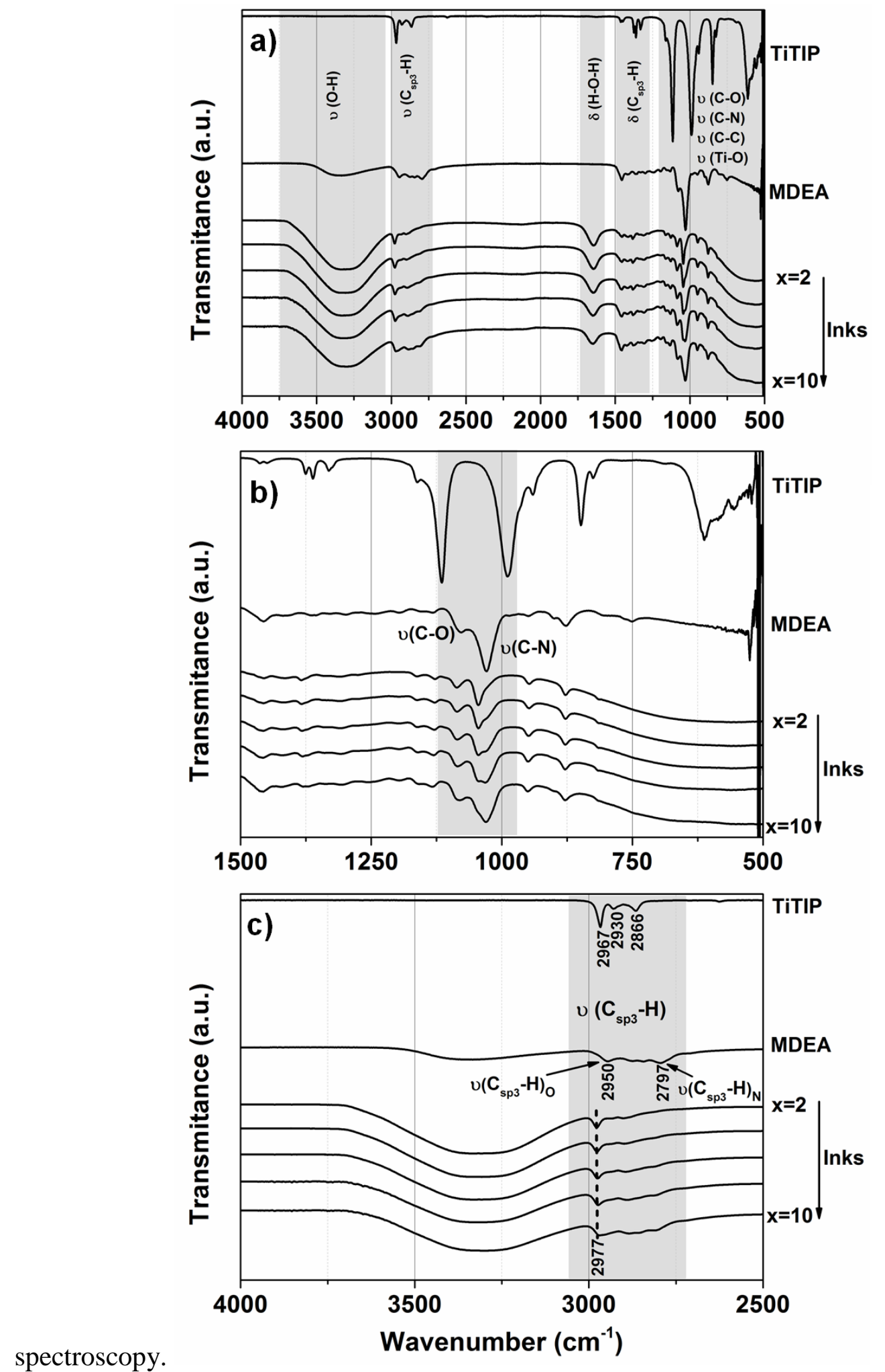


Figure 3(a) shows IR spectra for the two starting compounds (TiTIP and MDEA) and for the five developed inks in the entire range of frequencies explored. For the five inks and for the MDEA the broad bands attributed to the vibrational stretching of $\mathrm{O}-\mathrm{H}$ bonds are observed in a wide range of frequency, centered at around $3350 \mathrm{~cm}^{-1}$. These absorptions are significantly intense for the developed inks because of the presence of water, responsible also for the absorption at $1650 \mathrm{~cm}^{-1}$, due to the H-O$\mathrm{H}$ bending. The characteristics bands for the vibrational stretching (in the broad range of 2980-2780 $\mathrm{cm}^{-1}$ ) and bending (in the broad range of $1450-1325 \mathrm{~cm}^{-1}$ ) for $\mathrm{C}_{\mathrm{sp} 3}-\mathrm{H}$ bonds can be identified for all the materials investigated. Eventually the stretching for the $\mathrm{C}-\mathrm{O}, \mathrm{C}-\mathrm{C}$, and Ti-O bonds are observed in the characteristic range of frequency $\left(1110-600 \mathrm{~cm}^{-1}\right)$. The stabilization of the alkoxide in the aqueous solution is here identified by following the variation of the bands associated with stretching $v(\mathrm{C}-\mathrm{O})$ and $v(\mathrm{C}-\mathrm{N})$. Figure $3(\mathrm{~b})$ shows the same spectra in a narrower range of frequencies $\left(1500-500 \mathrm{~cm}^{-1}\right)$. In the spectra of pure MDEA, the two bands are centered at $1076(\mathrm{v}(\mathrm{C}-\mathrm{O}))$ and $1028(\mathrm{v}(\mathrm{C}-\mathrm{N})) \mathrm{cm}^{-1}$, respectively. Since titanium is less electronegative than $\mathrm{O}$ and $\mathrm{N}$, both the $v(\mathrm{C}-\mathrm{O})$ and $v(\mathrm{C}-\mathrm{N})$ bands are shifted to higher frequency (see positions of the peaks in Table 2). The largest shift is obtained for the Ink2. As the amount of MDEA increases, the band associated with $v(\mathrm{C}-\mathrm{O})$ is only slightly shifted to lower frequencies without reaching again its original positions. This likely indicates that the alcoholic functions of MDEA, from low to high concentrations, are not free but coordinated with Ti atom of the alkoxide. As further support for this, the stretching of the $\left(\mathrm{C}_{\mathrm{sp} 3}-\mathrm{H}\right)$ bonds next to the $\mathrm{C}-\mathrm{O}$ functions coordinated with $\mathrm{Ti}$, are also shifted to higher frequencies $\left(2977 \mathrm{~cm}^{-1}\right)$ with respect to the same bonds in free MDEA (see also Figure 3(c)). By contrast, the band associated with $v(\mathrm{C}-\mathrm{N})$ modes exhibits a splitting into two distinct absorptions. The additional band, located at lower frequency, initially appears as a shoulder, visible starting from Ink4. Its intensity and resolution increase with the content of MDEA until in Ink10 it is the main signals, centered at $1030 \mathrm{~cm}^{-1}$, corresponding to the frequency $v(\mathrm{C}-\mathrm{N})$ in pure MDEA (see Table 2). The $v(\mathrm{C}-\mathrm{N})$ band centered at $1044 \mathrm{~cm}^{-1}$ in Ink2 is observed to follow an 
opposite evolution with its intensity and resolution progressively weakening until it appears as a shoulder in Ink10. This likely indicates that, as the amount of MDEA increases, a growing fraction of amine functions are not involved in a coordination of the Titanium atom and thus they result free.

In summary, according to FTIR spectra, different complexes are generated in the water/ethanol solution depending on the MDEA content. Possible coordination complexes are also represented in Figure 4. Specifically, when the $[\mathrm{MDEA}] /[\mathrm{Ti}]$ molar ratio is equal to 2, both the amine and alcoholic functions are involved in the coordination of the Ti central atom. In these conditions MDEA acts as tridentate ligands favoring the coordinative saturation of the Titanium atoms [27] (Figure 4(c)). Despite the high stability of the obtained species, over time the hydrolysis/condensation process is occurring (viscosity increases and the flow index deviates from the unit) as the solvent mostly consists of water. At higher complexation ratio (e.g. 6), an increasing fraction of amine functions are free, likely as consequence of a bridging coordination of MDEA via the alcoholic functions as indicated in Figure 4(d) and 4(e). Accordingly, the absorption $v(\mathrm{C}-\mathrm{N})$ due to free amine functions is dominant. Extended complexes are thus generated with a consequent increasing of the viscosity.

Based on the indications obtained on the long stability properties, only Ink4 was further explored and printed

\subsection{Phase and printing characterization}

In a processing point of view, both fresh and aged inks are printable thus no influence of aging on the printing or material characterization is to be expected. All characterization and printing have been performed on a 600 hour aged ink. Crystallization behavior for ink4 was explored by in-situ XRD experiments at different temperature. Figure 5 shows XRD patterns at increasing temperature for Ink4 sample deposited as drops on the holder sample (Pt wire, used as reference). In all the patterns the signals deriving from Pt are identified. The anatase crystallographic phase is already detectable at 
temperature as low as $350{ }^{\circ} \mathrm{C}$. At higher temperatures, the peaks associated with the anatase phase become sharper and more intense indicating an increasing in the crystallite size. As expected, at $700{ }^{\circ} \mathrm{C}$ transformation from anatase to rutile phase occurs. Thermal analysis (DTA/TG) performed on the ink show that mass loss relative to solvent evaporation and chelating agent is completed at $350^{\circ} \mathrm{C}$ with an overall loss of ca. $80 \%$ of the starting weight (data not shown here). Based on these results, a crystallization temperature of $400{ }^{\circ} \mathrm{C}$ was then selected for the printings and crystallite size for the material treated at $400{ }^{\circ} \mathrm{C}$ was estimated via Scherrer equation to be around $7 \mathrm{~nm}$.

The optimized Ink4 was deposited on three substrates with different surface energies, i.e., ITO (36 mJ $\left.\mathrm{m}^{-2}\right)$, polycrystalline alumina $\left(65 \mathrm{~mJ} \mathrm{~m}^{-2}\right)$ and soda lime glass $\left(70 \mathrm{~mJ} \mathrm{~m}^{-2}\right)$, by using two printers and print heads. The two chosen printers use two different printing principle, i.e. thermal and piezoelectric inkjet printing. In thermal inkjet printing, ink solvent evaporation using a heating element induces droplet formation at the nozzle due to overpressure while piezoelectric inkjet printing principle is based on squeezing a droplet out of a nozzle by applying a electric current to a piezoelectric material [43]. The ejection principle being different for both technologies, ink requirements for droplet ejection will be different. Inks designed for thermal inkjet printing need to be heat resistant, which limits the choice of inks which can be deposited. In piezoelectric systems, suitable viscosity and surface tension will play a crucial role in the droplet formation process. In general, there is a greater choice of inks for piezoelectric inkjet printing than for thermal inkjet printing. Figure 6 shows a selection of features at the printing. Particularly, Figure 6 (a) shows the typical shape of the Ink4 ejected droplet, as observed using the fiducial camera mounted on the Pixdro printer. Remarkably the droplet exhibits a sphere-like shape with diameter of $c a .35 \mu \mathrm{m}$. The snapshot is taken at $c a .530 \mu \mathrm{m}$ from the nozzle where the droplet does not exhibit any presence of satellite droplets. This result is consistent with the ability to print as indicated by the printability domain $1<Z<10$, which for Ink4, is $Z=1.02$. Figures 6 (b)-(c) show complex as deposited printings and defined shapes, such as letters and numbers on different substrates: 
Figure 6(b) shows the printed "DTU" letters (Danmarks Tekniske Universitet) and "TiO ${ }_{2}$ with different size on alumina substrate. This is done by using an inexpensive HP printer which indeed has a limited resolution and quality of the printing (see other examples of printing flaws by that printer in [12]). However, while letter and numbers appear rather clear in millimeter scale (first raw at the top) the precision is lost at the micron scale (last raw at the bottom). Angles and lines in the print resulted rather homogeneous and continuous in large size printings. On the other hand, Figure 6(c) shows a rather small printing, i.e. the number " 61 ", on ITO using the Pixdro printer. The higher quality of this printing with respect of the HP lays on the size of the characters with typical size between 100 and 400 $\mu \mathrm{m}$ as well as on complexity of the shape, e.g. sharp corners and smooth bending in the numbers. Similar results were observed on the soda-lime glass substrates, indicating a good coverage of the ink on substrates with surface tension in the range $36-70 \mathrm{~mJ} \mathrm{~m}^{-2}$. Ink4 was thus successfully deposited using both printing techniques (thermal and piezoelectric) despite the different requirements needed in terms of ink for both techniques, especially in the case of thermal inkjet printing.

Figures $6(\mathrm{~d})$ and $6(\mathrm{e})$ show the effect of calcination at $400^{\circ} \mathrm{C}$ for 1 hour after printing. In Figure $6(\mathrm{~d})$, the "DTU" letters deposited are still perfectly visible and recognizable. However the prints definition is not as sharp as in the as printed material (compare Figure 6(b) and 6(d)). Possibly, this is due to shrinkage of the ink as well as to possible wetting issue developed during the calcination. Similar features were also measured on a chessboard pattern in Figure 6(e). In this case, the printing resulted stable and exhibited continuous squares connected at each corner. The continuity at the printing, e.g. at the letters (d) and the squares corners (e), indicates that a relatively low shrinkage in the plane directions occurred after calcination. This is a remarkable result for the reactive ink, especially considering that large mass loss ( $\sim 80 \%)$, measured at the TG. Considering the $\mathrm{TiO}_{2}$ theoretical density (4.23 $\mathrm{g} \mathrm{ml}^{-1}$ ) and the other organic components of the solutions, such a loss corresponds to a large change of volume in the printing after calcination, i.e. $>120$ vol. \%. Such a large shrinkage is indeed 
critical and these results confirm the importance of controlling printability parameters. For the microstructural features of the printing, Figure 7 shows SEM images after calcination. Particularly, Figure 7(a) shows the top view of an Ink4 layer deposited on ITO coated glass by inkjet printing and calcined at $400{ }^{\circ} \mathrm{C}$ for 1 hour. The film resulted continuous and homogeneous on the substrate and microstructural feature could be observed only in nanoscale at high magnification (inset Figure 7(a)), showing a dense polycrystalline deposition. Average particle size is estimated by picture analysis at 11 $\mathrm{nm} \pm 1 \mathrm{~nm}$ (based on 30 measurements from 2 different locations along the sample). Figure 7(b) and 7(c) show the printed layer at a cold fracture: in Figure 7(a), a typical thickness of a single deposition by the HP was estimated to be around $480 \mathrm{~nm}$, while, in Figure 7(c), high resolution at the cross section reveals a dense and polycrystalline morphology of the film. This is kept throughout the deposition without any detectable flaws.

\section{Conclusions}

A stable aqueous sol gel based ink for inkjet printing using a nucleophilic ligand to delay hydrolysis and condensation reactions was successfully designed by rheology. Printability and stability were optimized by variating the amount of MDEA as nucleophilic ligand and measuring ink viscosity over time. The use of the MDEA to achieve the proper printability is a balance between an effective coordination of the metal center in the metal alkoxide, at low concentration, $\mathrm{x}<2$, and an early organic-inorganic polymerization of TiTIP and MDEA at high concentrations, $x>>$. An optimized ink at $\mathrm{x}=4$ was thus proven by printing small complex shapes (e.g. letters) and thin dense layer of $c a$ $500 \mathrm{~nm}$ in thickness, on various substrates with surface tension in the $36-170 \mathrm{~mJ} \mathrm{~m} \mathrm{~m}^{-2}$ range. The ink is purified from the organics at $\mathrm{ca} .400{ }^{\circ} \mathrm{C}$ while phase transitions from amorphous Titania to anatase, and from anatase to rutile, occur at $400^{\circ} \mathrm{C}$ and at $700{ }^{\circ} \mathrm{C}$, respectively.

\section{Acknowledgment}


The authors would like to thank Kurt Engelbrecht, Quentin Hanniet and Gaëtan Guellec for their precious assistance in experimentals.

\section{References}

[1] H. Sirringhaus, High-Resolution Inkjet Printing of All-Polymer Transistor Circuits, Science (80. ). 290 (2000) 2123-2126. doi:10.1126/science.290.5499.2123.

[2] M. Singh, H.M. Haverinen, P. Dhagat, G.E. Jabbour, Inkjet printing-process and its applications., Adv. Mater. 22 (2010) 673-85. doi:10.1002/adma.200901141.

[3] D. Tobjörk, R. Österbacka, Paper electronics., Adv. Mater. 23 (2011) $1935-61$. doi:10.1002/adma.201004692.

[4] A.D. Taylor, E.Y. Kim, V.P. Humes, J. Kizuka, L.T. Thompson, Inkjet printing of carbon supported platinum 3-D catalyst layers for use in fuel cells, J. Power Sources. 171 (2007) 101106. doi:10.1016/j.jpowsour.2007.01.024.

[5] T. Wang, B. Derby, Ink-Jet Printing and Sintering of PZT, J. Am. Ceram. Soc. 88 (2005) 20532058. doi:10.1111/j.1551-2916.2005.00406.x.

[6] H. Minemawari, T. Yamada, H. Matsui, J. Tsutsumi, S. Haas, R. Chiba, R. Kumai, T. Hasegawa, Inkjet printing of single-crystal films., Nature. 475 (2011) 364-367. doi:10.1038/nature10313.

[7] J. Ebert, E. Ozkol, A. Zeichner, K. Uibel, O. Weiss, U. Koops, R. Telle, H. Fischer, Direct inkjet printing of dental prostheses made of zirconia., J. Dent. Res. 88 (2009) 673-676. doi:10.1177/0022034509339988.

[8] D. Kim, S. Jeong, J. Moon, K. Kang, Ink-Jet Printing of Silver Conductive Tracks on Flexible Substrates, Mol. Cryst. Liq. Cryst. $459 \quad$ (2006) 45/[325]-55/[335]. doi:10.1080/15421400600930458.

[9] J. Cheon, J. Lee, J. Kim, Inkjet printing using copper nanoparticles synthesized by electrolysis, Thin Solid Films. 520 (2012) 2639-2643. doi:10.1016/j.tsf.2011.11.021.

[10] T. Kawase, T. Shimoda, C. Newsome, H. Sirringhaus, Inkjet printing of polymer thin film transistors, 439 (2003) 279-287. doi:10.1016/S0040-6090(03)00801-0.

[11] G. Deok, K. Chean, K. Bae, H. Jong, S. Won, J. Son, J. Hyung, Fabrication of lanthanum strontium cobalt ferrite ( LSCF ) cathodes for high performance solid oxide fuel cells using a low price commercial inkjet printer, J. Power Sources. 306 (2016) 503-509. doi:10.1016/j.jpowsour.2015.12.067.

[12] V. Esposito, C. Gadea, J. Hjelm, D. Marani, Q. Hu, K. Agersted, S. Ramousse, S.H. Jensen, Fabrication of thin yttria-stabilized-zirconia dense electrolyte layers by inkjet printing for high performing solid oxide fuel cells, J. Power Sources. 273 (2015) 89-95. doi:10.1016/j.jpowsour.2014.09.085.

[13] R. Cobas, S. Muñoz-pérez, S. Cadogan, M.C. Ridgway, X. Obradors, Surface Charge Reversal 
Method for High-Resolution Inkjet Printing of Functional Water-Based Inks, 25 (2015) 768775. doi:10.1002/adfm.201401638.

[14] T. Jungst, W. Smolan, K. Schacht, T. Scheibel, J. Groll, Strategies and Molecular Design Criteria for 3D Printable Hydrogels, Chem. Rev. 116 (2016) 1496-1539. doi:10.1021/acs.chemrev.5b00303.

[15] M. Michálek, G. Blugan, T. Graule, J. Kuebler, Comparison of aqueous and non-aqueous tape casting of fully stabilized $\mathrm{ZrO} 2$ suspensions, Powder Technol. 274 (2015) 276-283. doi:10.1016/j.powtec.2015.01.036.

[16] A. Akbari-fakhrabadi, R. V Mangalaraja, F.A. Sanhueza, R.E. Avila, S. Ananthakumar, S.H. Chan, Nanostructured $\mathrm{Gd}$ e $\mathrm{CeO} 2$ electrolyte for solid oxide fuel cell by aqueous tape casting, J. Power Sources. 218 (2012) 307-312. doi:10.1016/j.jpowsour.2012.07.005.

[17] J.M. Lebeau, Y. Boonyongmaneerat, Comparison study of aqueous binder systems for slurrybased processing, Mater. Sci. Eng. A. 458 (2007) 17-24. doi:10.1016/j.msea.2007.01.112.

[18] I.M. Hutchings, Inkjet technology for digital fabrication, Wiley, 2013.

[19] E.M. Hamad, S.E.R. Bilatto, N.Y. Adly, D.S. Correa, B. Wolfrum, M.J. Schöning, A. Offenhäusser, A. Yakushenko, Lab on a Chip dielectric inks for microfluidic devices $†$, Lab Chip. 16 (2016) 70-74. doi:10.1039/C5LC01195G.

[20] D.A. Gregory, Y. Zhang, P.J. Smith, X. Zhao, S.J. Ebbens, Reactive Inkjet Printing of Biocompatible Enzyme Powered Silk Micro-Rockets, Mater. Views. (2016) 4048-4055. doi:10.1002/smll.201600921.

[21] K. Black, J. Singh, D. Mehta, S. Sung, C.J. Sutcliffe, P.R. Chalker, Silver Ink Formulations for Sinter- free Printing of Conductive Films, Nat. Publ. Gr. (2016) 1-7. doi:10.1038/srep20814.

[22] J.M. Chem, Z. Kao, Y. Hung, Y. Liao, Formation of conductive silver films via inkjet reaction system, J. Mater. Chem. (2011) 18799-18803. doi:10.1039/c1jm13506f.

[23] B.S. Cook, Y. Fang, S. Kim, T. Le, W.B. Goodwin, K.H. Sandhage, M.M. Tentzeris, Inkjet Catalyst Printing and Electroless Copper Deposition for Low-Cost Patterned Microwave Passive Devices on Paper, 9 (2013) 669-676. doi:10.1007/s13391-013-3027-0.

[24] L.L. Hench, J.K. West, The sol-gel process, Chem. Rev. 90 (1990) 33-72. doi:10.1021/cr00099a003.

[25] C. Sanchez, J. Livage, M. Henry, F. Babonneau, Chemical modification of alkoxide precursors, J. Non. Cryst. Solids. 100 (1988) 65-76.

[26] T. Kemmit, N.I. Al-Salim, G.J. Gainsford, CHEMISTRY N -Methyldiethanolamine-Modified Titanium Isopropoxide :, Aus. J. Chem. 55 (2002) 513-517. doi:10.1071/CH02087.

[27] N. Martín-Arbella, I. Bretos, R. Jiménez, M.L. Calzada, R. Sirera, Metal complexes with Nmethyldiethanolamine as new photosensitive precursors for the low-temperature preparation of ferroelectric thin films, J. Mater. Chem. 21 (2011) 9051-9059. doi:10.1039/c1jm10846h.

[28] T. Nguyen, Y. Chen, J. He, Preparation of inkjet-printed titanium monoxide as p-type absorber 
layer for photovoltaic purposes, Thin Solid Films. $572 \quad$ (2014) 8-14. doi:10.1016/j.tsf.2014.09.054.

[29] M. Arin, J. Watté, G. Pollefeyt, K. De Buysser, Low temperature deposition of TiO 2 layers from nanoparticle containing suspensions synthesized by microwave hydrothermal treatment, J. Sol-Gel Sci. Technol. 66 (2013) 100-111. doi:10.1007/s10971-013-2972-2.

[30] M. Černá, M. Veselý, P. Dzik, C. Guillard, E. Puzenat, M. Lepičová, Fabrication, characterization and photocatalytic activity of $\mathrm{TiO} 2$ layers prepared by inkjet printing of stabilized nanocrystalline suspensions, Appl. Catal. B Environ. 138-139 (2013) 84-94. doi:10.1016/j.apcatb.2013.02.035.

[31] I. Fasaki, K. Siamos, M. Arin, P. Lommens, I. Van Driessche, S.C. Hopkins, B.A. Glowacki, I. Arabatzis, Applied Catalysis A : General Ultrasound assisted preparation of stable water-based nanocrystalline $\mathrm{TiO} 2$ suspensions for photocatalytic applications of inkjet-printed films, "Applied Catal. A, Gen. 411-412 (2012) 60-69. doi:10.1016/j.apcata.2011.10.020.

[32] M. Morozova, P. Kluson, J. Krysa, P. Dzik, M. Vesely, O. Solcova, Thin TiO2 films prepared by inkjet printing of the reverse micelles sol-gel composition, Sensors Actuators B Chem. 160 (2011) 371-378. doi:10.1016/j.snb.2011.07.063.

[33] M. Arin, P. Lommens, N. Avci, S.C. Hopkins, K. De Buysser, I.M. Arabatzis, I. Fasaki, D. Poelman, I. Van Driessche, Inkjet printing of photocatalytically active $\mathrm{TiO} 2$ thin films from water based precursor solutions, J. Eur. Ceram. Soc. 31 (2011) 1067-1074. doi:10.1016/j.jeurceramsoc.2010.12.033.

[34] P. Dzik, M. Veselý, J. Chomoucka, Thin Layers of Photocatalytic TiO2 Prepared by Inkjet Printing of a Solgel Precursor Thin Layers of Photocatalytic TiO 2 Prepared by Inkjet Printing of a Sol-, J. Adv. Oxid. Technol. 13 (2010) 1-12.

[35] B. Derby, Inkjet Printing of Functional and Structural Materials: Fluid Property Requirements, Feature Stability, and Resolution, Annu. Rev. Mater. Res. 40 (2010) 395-414. doi:10.1146/annurev-matsci-070909-104502.

[36] A. Monshi, Modified Scherrer Equation to Estimate More Accurately Nano-Crystallite Size Using XRD, World J. Nano Sci. Eng. 02 (2012) 154-160. doi:10.4236/wjnse.2012.23020.

[37] R.A.S. Ferreira, Simple measurement of surface free energy using a web cam, Rev. Bras. Ensino Fis. 3312 (2012).

[38] G.D. Martin, S.D. Hoath, I.M. Hutchings, Inkjet printing - the physics of manipulating liquid jets and drops, J. Phys. Conf. Ser. 105 (2008) 012001. doi:10.1088/1742-6596/105/1/012001.

[39] Helmut Kipphan, Handbook of Print Media, 2001.

[40] D. Jang, D. Kim, J. Moon, Influence of fluid physical properties on ink-jet printability., Langmuir. 25 (2009) 2629-35. doi:10.1021/la900059m.

[41] S. Doeuff, M. Henry, C. Sanchez, J. Livage, Hydrolysis of titanium alkoxides: Modification of the molecular precursor by acetic acid, J. Non. Cryst. Solids. 89 (1987) 206-216. doi:10.1016/S0022-3093(87)80333-2. 
[42] D. Marani, J. Hjelm, M. Wandel, Rheological analysis of stabilized cerium-gadolinium oxide (CGO) dispersions, J. Eur. Ceram. Soc. $34 \quad$ (2014) 695-702. doi:10.1016/j.jeurceramsoc.2013.09.022.

[43] A. Lesch, F. Cortés-Salazar, V.C. Bassetto, V. Amstutz, H.H. Girault, Inkjet Printing Meets Electrochemical Energy Conversion, Chim. Int. J. Chem. 69 (2015) 284-289. doi:10.2533/chimia.2015.284.

Table 1: Inks printability after 4 hours. 600 hours and 1200 hours of aging $\left(\rho=0.95 . \mathrm{cm}^{-3}, \mathrm{a}=20 \mu \mathrm{m}\right.$ for all measurements)

\begin{tabular}{c||ccc||ccc||ccc}
\hline \multicolumn{1}{l||}{} & \multicolumn{3}{c||}{$\mathrm{t}=4$ hours } & \multicolumn{3}{c||}{$\mathrm{t}=600$ hours } & \multicolumn{3}{c}{$\mathrm{t}=1200$ hours } \\
\hline & $\eta(\mathrm{mPa} . \mathrm{s})$ & $\sigma(\mathrm{mN} / \mathrm{m})$ & $\mathrm{Z}$ & $\eta(\mathrm{mPa} . \mathrm{s})$ & $\sigma(\mathrm{mN} / \mathrm{m})$ & $\mathrm{Z}$ & $\eta(\mathrm{mPa} . \mathrm{s})$ & $\sigma(\mathrm{mN} / \mathrm{m})$ & $\mathrm{Z}$ \\
\hline Ink2 & 6.22 & 27.01 & 3.64 & 36.50 & 27.43 & 0.63 & 66.5 & 27.3 & 0.34 \\
\hline Ink4 & 4.79 & 27.38 & 4.76 & 22.20 & 26.87 & 1.02 & 27.1 & 26.9 & 0.83 \\
\hline Ink6 & 6.47 & 28.77 & 3.61 & 44.91 & 28.13 & 0.51 & 56.4 & 28.3 & 0.41 \\
\hline Ink8 & 10.13 & 29.79 & 2.35 & 126.00 & 30.09 & 0.19 & 262 & 29.9 & 0.09 \\
\hline Ink10 & 1.64 & 30.48 & 1.76 & 145.00 & 30.94 & 0.17 & 421 & 30.9 & 0.06 \\
\hline
\end{tabular}

Table 2: v(C-O) and v(C-N) FTIR peaks position in MDEA and in the developed inks (600 hours of ageing).

\begin{tabular}{|c|c|c|c|}
\hline \multirow[b]{2}{*}{ MDEA } & \multirow{2}{*}{$\begin{array}{c}v(\mathrm{C}-\mathrm{O}) \\
\mathrm{cm}^{-1}\end{array}$} & \multicolumn{2}{|c|}{$\begin{array}{c}v(\mathrm{C}-\mathrm{N}) \\
\mathrm{cm}^{-1}\end{array}$} \\
\hline & & 1028 & \\
\hline Ink2 & 1088 & 1044 & \\
\hline Ink4 & 1085 & 1044 & shoulder \\
\hline Ink6 & 1085 & 1044 & 1029 \\
\hline Ink8 & 1084 & 1043 & 1029 \\
\hline Ink10 & 1083 & shoulder & 1030 \\
\hline
\end{tabular}


Figures

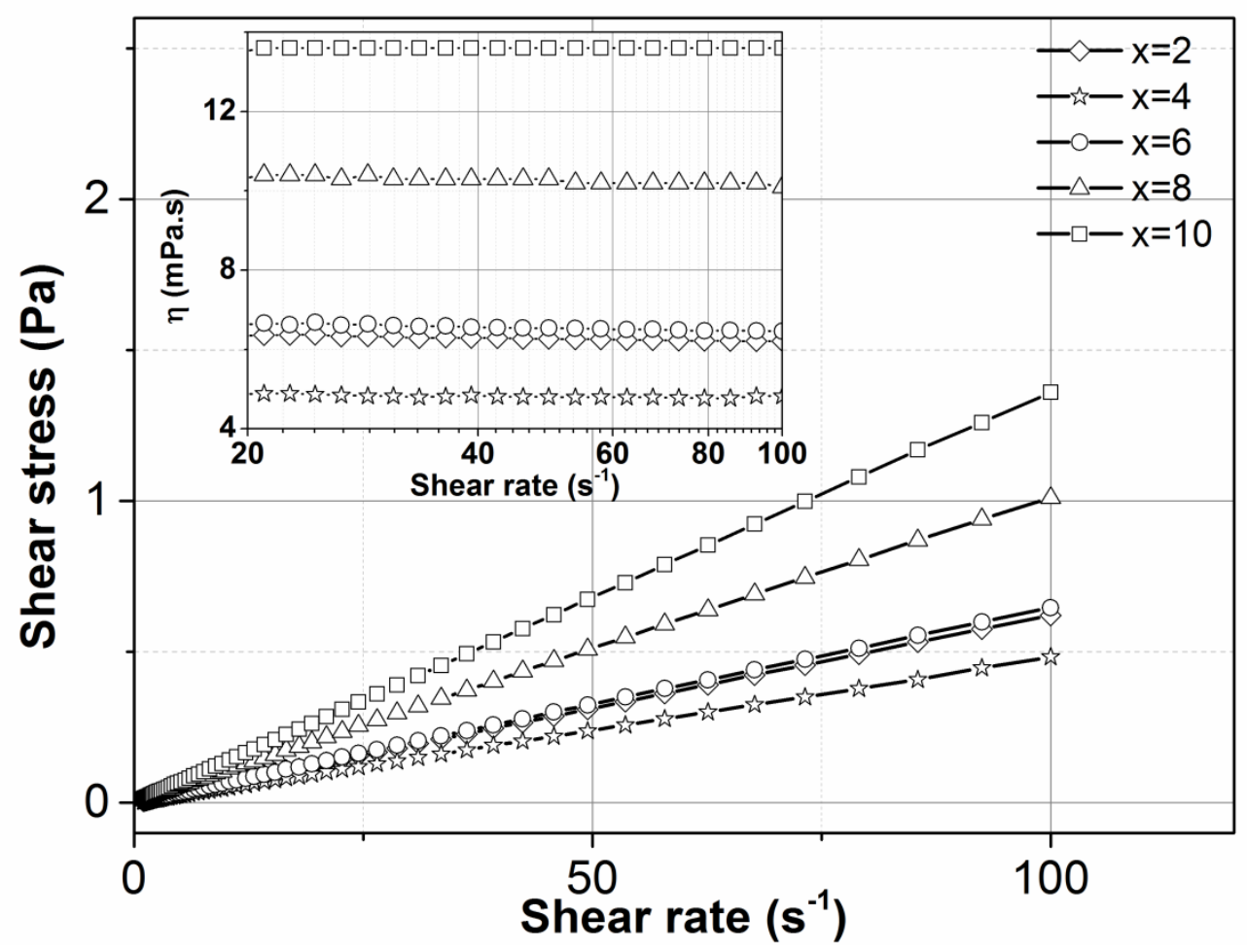

Figure 1 :Flow curves and viscosity curves (inset) for the five inks developed (4 hours after preparation). 
a)
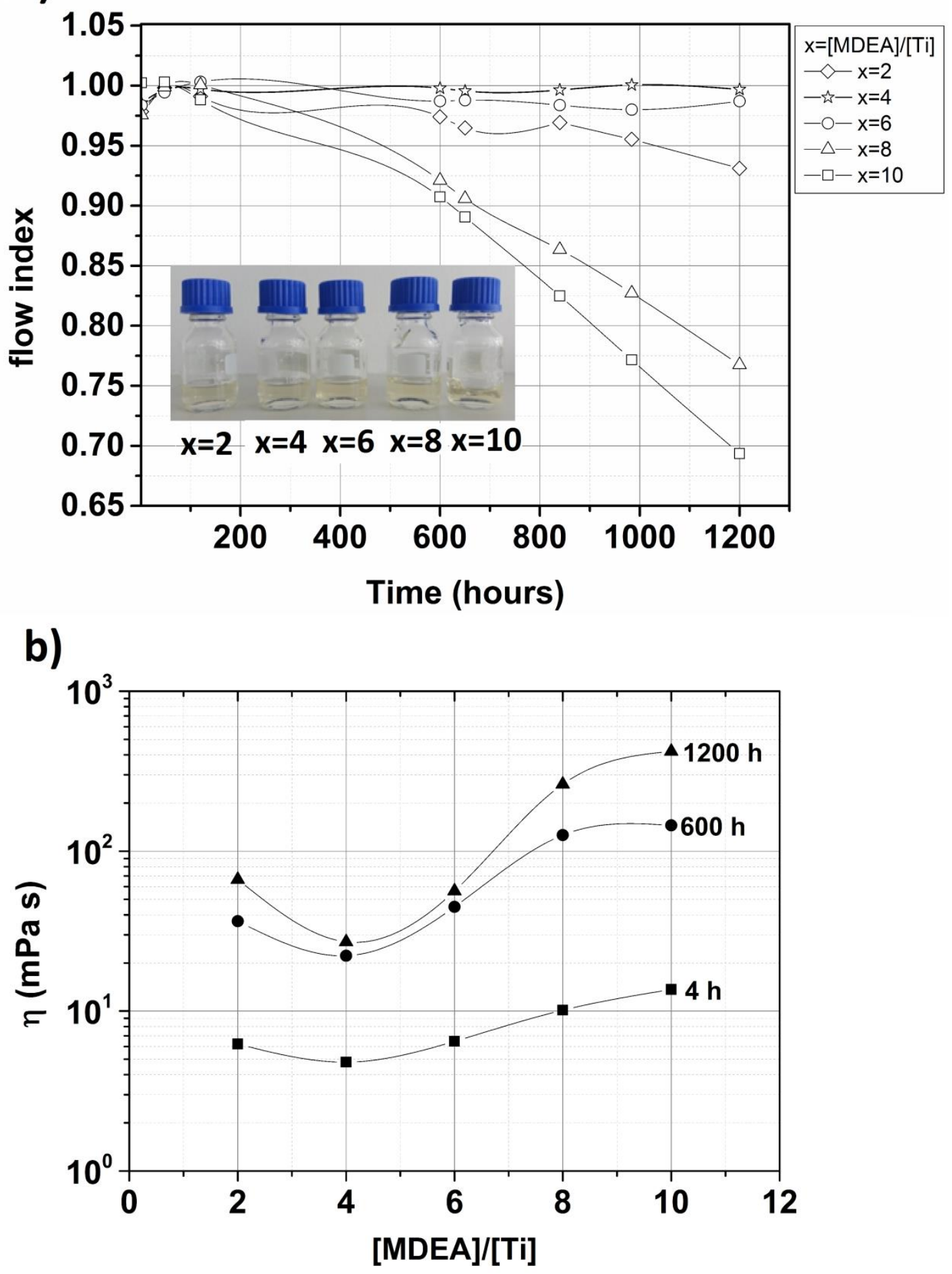

Figure 2: Inks flow index measured over resting time (a) (inset: aspect of the inks after 1200 hours of storage) and inks viscosity ( $\dot{\gamma}=100 \mathrm{~s}-1)$ at 3 different resting time versus complexation ratio (b) 

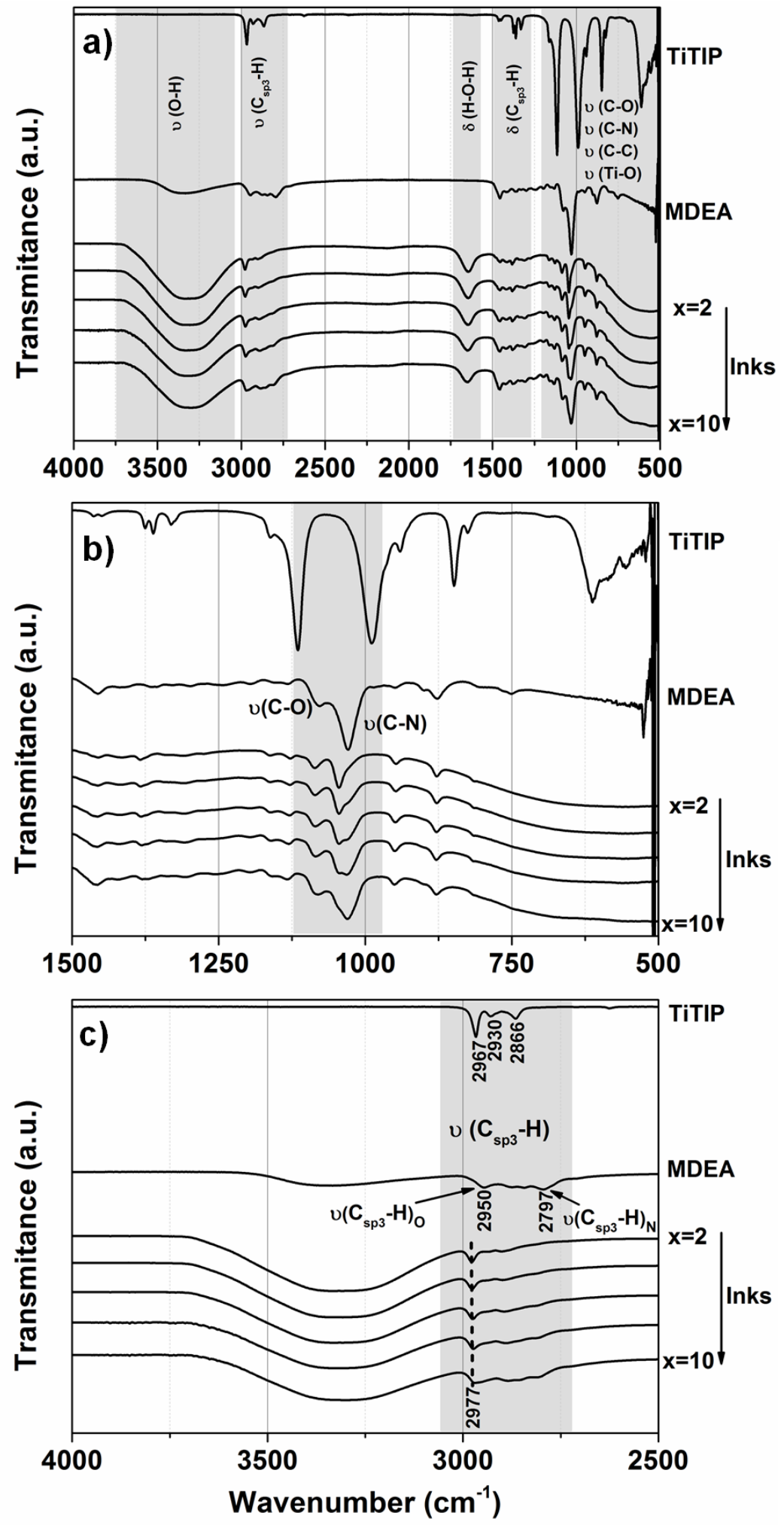

Figure 3 : FTIR spectra for the inks after 600 hours resting (a), and detailed view of the pattern in the ranges $1500-1000 \mathrm{~cm}-1(\mathrm{~b})$ and $3200-2500 \mathrm{~cm}-1(\mathrm{c})$. 
a)

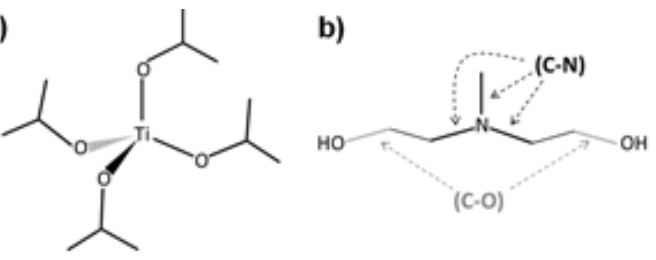

c)

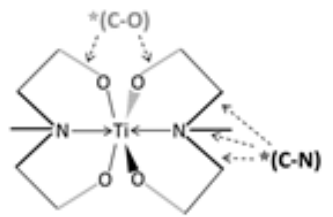

$x=2$
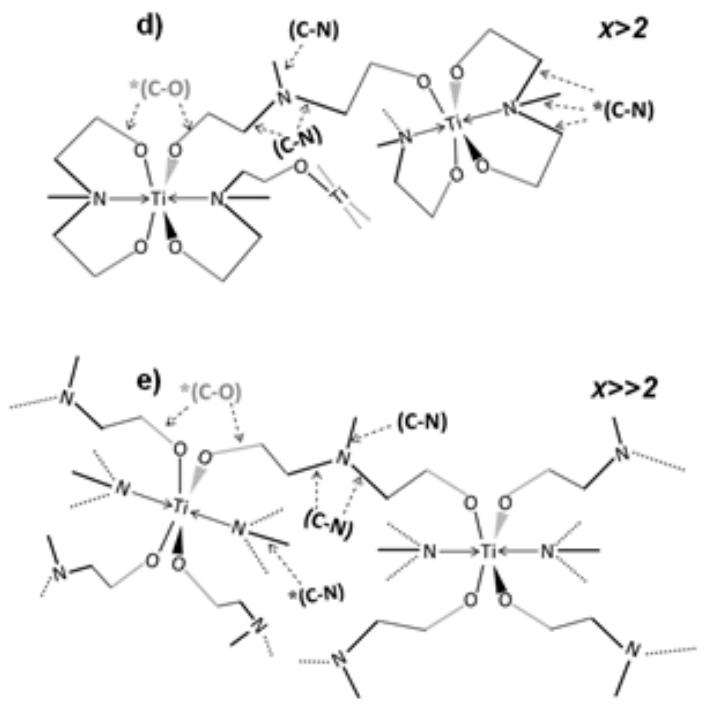

Figure 4: Chemical structures of a) Titanium isopropoxide (TiTIP), b) MDEA, and c), d), e) possible complexes formed at different [MDEA]/[Ti] molar ratio 


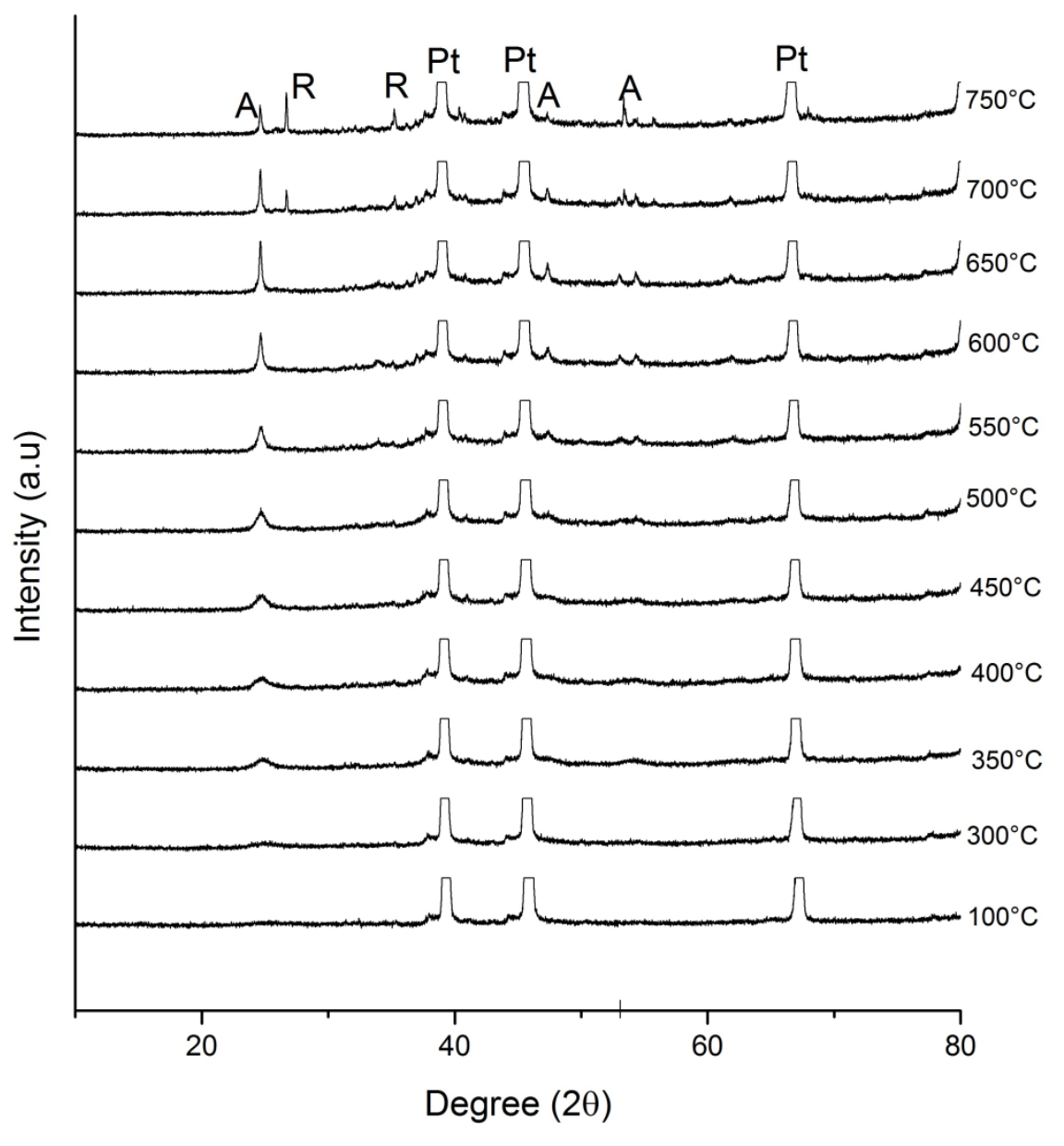

Figure 5: XRD patterns of Ink4 (600 hours of resting) at different temperature ( $A=$ anatase; $R=$ rutile, $\mathrm{Pt}=$ Platinum $)$. 


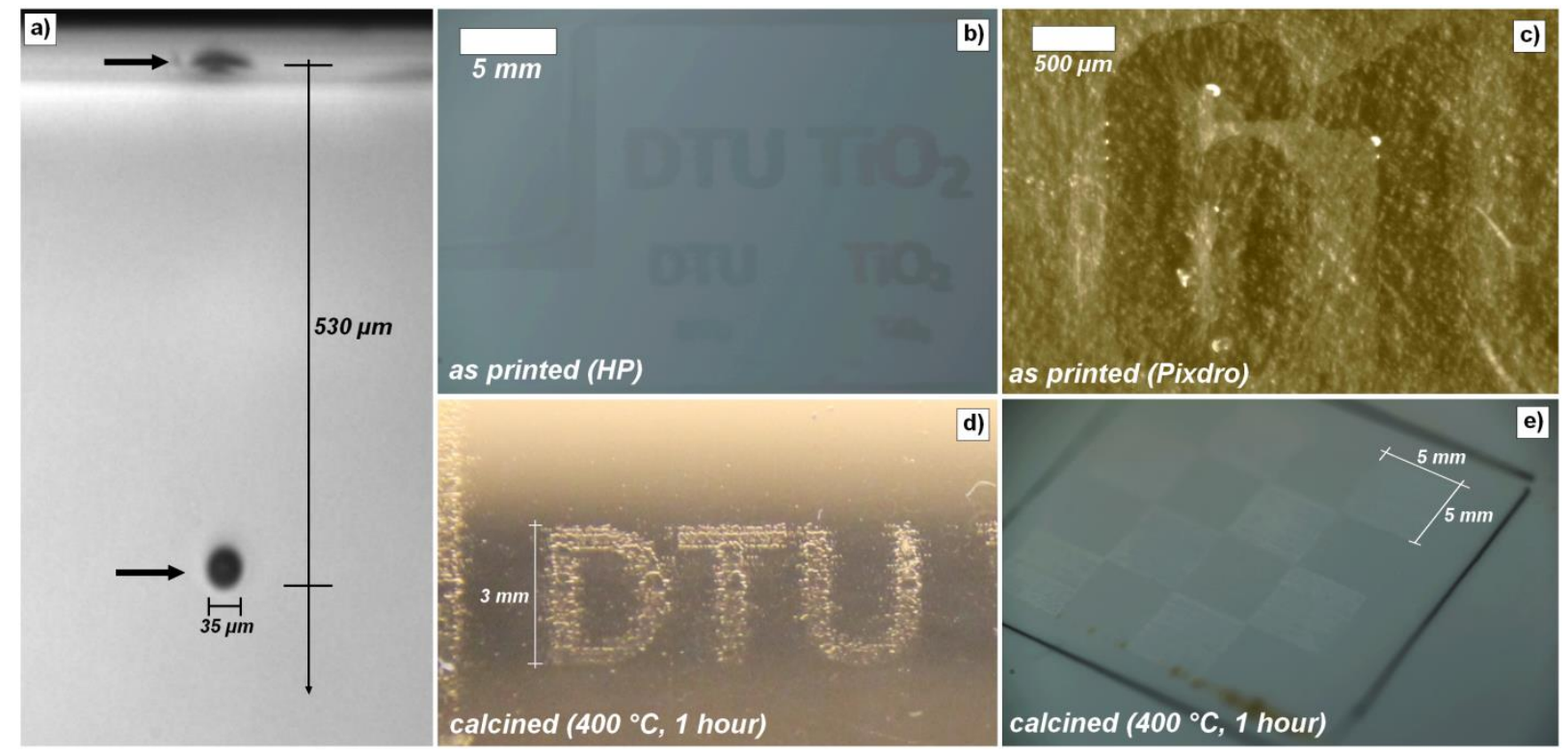

Figure 6: (a) Droplet ejected from Pixdro nozzle, (b) as deposited "DTU" and "TiO 2 " letters onto alumina (HP), (c) as deposited number "61" onto ITO (Pixdro), (d) letters printed (HP) onto alumina and calcined at $400^{\circ} \mathrm{C}$, (e) chessboard pattern printed (HP) onto ITO and calcined at $700^{\circ} \mathrm{C}$. 


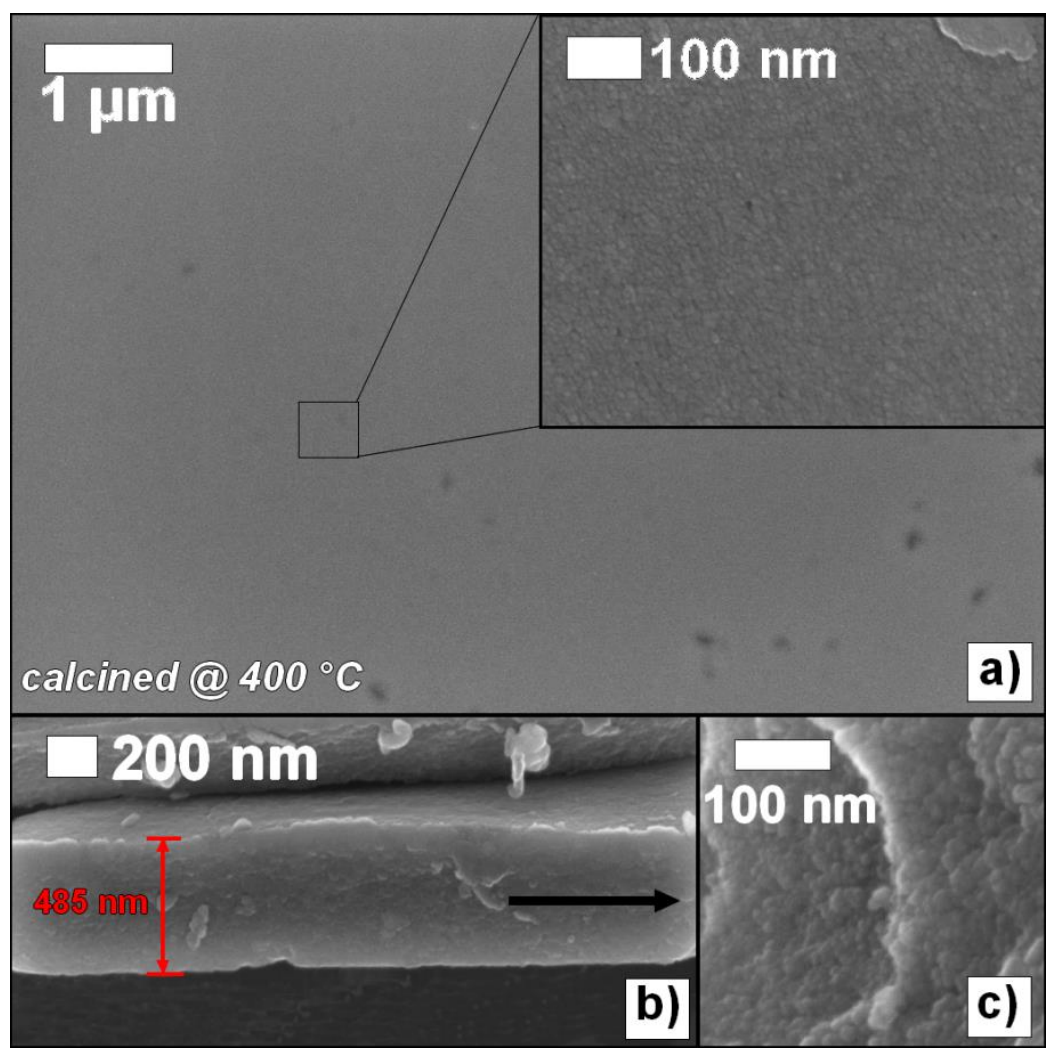

Figure 7: SEM images of the printed layer surface at low (a) and high ((a) inset) magnification, followed by the layer cross section (b) together with a broken piece of thin film (c). 